\title{
Antidiabetic and antihyperlipidemic activities of Cucumis melo var. momordica fruit extract on experimental animals
}

\author{
Arvind Kumar Srivastava*, Alok Mukerjee and Abhishek Tripathi
}

\begin{abstract}
Background: Diabetes mellitus is a major public health issue related to the irregular metabolism of carbohydrates, protein, and fat. It occurs due to insufficient insulin production and insulin action. Cucumis melo possesses several biological properties including antioxidant, anti-inflammatory, antibacterial, antihypothyroidism, and antiangiogenic activities. The objective of the present study was to determine the antidiabetic and antihyperlipidemic activities of Cucumis melo var. momordica fruit extract on experimental animals.

Result: Results show that treatment with C. melo fruit extract and fraction caused a reduction in blood glucose levels. Cucumis melo toluene fraction (CMTF) exhibited a significant $\left({ }^{*} P<0.05\right)$ reduction of blood glucose level on the 28th day, i.e., $122 \mathrm{mg} / \mathrm{dL}$, in comparison with the positive control group (streptozotocin (STZ)). However, the extract of $C$. melo showed less significant results in comparison with CMTF. Triglyceride, LDL, and VLDL levels were increased chronically due to STZ and were significantly $\left.{ }^{*} P<0.05\right)$ restored to $84.16,86.97$, and 19.73 , respectively, by CMTF in comparison with the positive control group (STZ in the dose of $55 \mathrm{mg} / \mathrm{kg}$ ). The extract-treated groups also showed similar results as CMTF, but their efficacy was lesser than CMTF.
\end{abstract}

Conclusion: It is can be concluded that C. melo fruits can be used as an effective antidiabetic and antihyperlipidemic drug.

Keywords: Cucumis melo, Streptozotocin, Diabetes, Triglyceride, Lipoproteins

\section{Background}

Diabetes mellitus is a metabolic syndrome, characterized by high blood glucose levels that affect life's standard, and imposes a huge economic burden in society [1]. It occurs it is due to insufficient insulin production and insulin action. It has become one of the major public health issues [2]. It has become the seventh leading cause of death worldwide [3]. Diabetes mellitus can be divided into two categories: type 1 diabetes mellitus (T1DM) and type 2 diabetes mellitus (T2DM) [4]. T1DM is an autoimmune disorder in which pancreatic $\beta$ cells are unable to produce sufficient insulin due to its destruction [5]. In T2DM, sufficient insulin is produced

\footnotetext{
* Correspondence: arvind.org@live.com

United Institute of Pharmacy, Naini, Prayagraj, Uttar Pradesh 211010, India
}

from $\beta$ cells, but cells become tolerant to use the available insulin, i.e., insulin resistance [6]. One of the major metabolic syndrome associated with diabetes is hypertriglyceridemia. It is the condition of increased triglyceride levels in the blood that makes the condition worse. Noticeably, the major adverse effect of hypertriglyceridemia is acute pancreatitis, in addition to other lipid abnormalities such as hypercholesterolemia, cardiovascular diseases, and obesity $[7,8]$. Diabetes is associated with lipid abnormalities in the body with reduced high-density lipoprotein (HDL) and raised low-density lipoprotein (LDL), very low-density lipoprotein (VLDL), and triglycerides (TG) levels [9].

Cucumis melo var. momordica (Roxb.) Duthie et Fuller is an ancient herb that belongs to the family Cucurbitaceae. It is a horticulture crop found across the globe $[10,11] . C$. 
melo is a native herb of India and used as a vegetable [12]. It has several varieties of fruit traits found in nature and largely cultivated for fruit production all over the world $[13,14]$. It has been used in the treatment of ulcers, bronchitis, eye infection, and fever due to the presence of active phytoconstituents [15]. The phytoconstituents present in $C$. melo are $\beta$-carotenes, multiflorenol, and a range of secondary metabolites including glycolipids, terpenoids, flavonoids, carbohydrates, and apocaretonoids [16, 17]. It possesses several biological properties including antioxidant, anti-inflammatory, antibacterial, antihypothyroidism, and antiangiogenic activities. The fruit peel extract of $C$. melo also possesses lipid-lowering properties [18]. Thus, the present study was designed to determine the antidiabetic and antihyperlipidemic activities of $C$. melo fruits based on its traditional medicinal uses by the ethnic groups and interrelationship between the pathophysiology of both diseases.

\section{Methods}

\section{Collection, identification, and authentication}

The ripe fruits of Cucumis melo var. momordica were collected from the gangatic areas of district Allahabad during the spring season. The fruits were identified and authenticated by the Botanical Survey of India with voucher specimen number GC 950221.

\section{Extraction of Cucumis melo fruits}

The fruits were peeled off, sliced, and dried under shade then grounded to make powder and sieved through a mesh size of $20(0.841 \mathrm{~mm})$. The coarse fruit powder of Cucumis melo momordica Duthie and Fuller was defatted with petroleum ether and extracted with ethanol as a solvent. The dried powder sample $(20 \mathrm{~g})$ was added into the solvent $(300 \mathrm{ml})$ and stirred for $24 \mathrm{~h}$. The solution was filtered using Whatman filter paper and evaporated the filtrate in an incubator at $40{ }^{\circ} \mathrm{C}$. The extract was dried in a rotary evaporator (Buchi) and stored at $40{ }^{\circ} \mathrm{C}$ until further use [19].

\section{Physicochemical evaluation}

Physiochemical parameters of Cucumis melo evaluated in this study were foreign matter, moisture content, total ash, water-soluble ash, acid insoluble ash, and swelling index. It was determined according to Mushtaq et al. [20].

\section{Reaction of different reagents with powdered drugs}

The powdered drug of C. melo was treated with several reagents such as sodium hydroxide $(\mathrm{NaOH})$, nitric oxide $\left(\mathrm{HNO}_{3}\right)$, hydrochloric acid $(\mathrm{HCl})$, sulfuric acid $\left(\mathrm{H}_{2} \mathrm{SO}_{4}\right)$, acetone, and chloroform $\left(\mathrm{CHCl}_{3}\right)$. It was further observed under UV and visible light to note the color produced after treatment using a microscope [21].

\section{Fluorescence analysis of $C$. melo powder}

Fluorescence analysis of $C$. melo powder was performed by exposing the powder to sunlight and UV rays (254 and $366 \mathrm{~nm}$ ), then it was treated with different reagents as described above.

\section{Experimental protocols \\ Animals}

A total of 48 male Wistar rats were used in the study weighing 200-240 g (14 weeks old). They were obtained from the animal house of the institute. The study was approved by the Institutional Animals Ethical Committee (No. UIP/IAEC/2014/April/23). Animals were fed with pelleted diet and water ad libitum.

\section{Acute toxicity study}

Acute toxicity study was performed according to the OECD guideline 423 .

\section{Design of experiment}

Animals were randomly divided into eight groups, and six animals were assigned to each group. Group 1 was the negative control (NC) group, which was a vehicletreated group; group 2 was the positive control (PC) group, which was a toxicity-induced group; group 3 was the standard group, which was a group treated with glibenclamide, $10 \mathrm{mg} / \mathrm{kg}$; groups 4 to 8 were the combined drug-treated groups in which group 4 was a Cucumis melo toluene fraction-treated (CMTF, $50 \mathrm{mg} / \mathrm{kg}$ ) group, group 5 was a Cucumis melo ethanolic extract-treated (CMEE 1, $400 \mathrm{mg} / \mathrm{kg}$ ) group, group 6 was a Cucumis melo ethanolic extract-treated (CMEE 2, $200 \mathrm{mg} / \mathrm{kg}$ ) group, group 7 was a Cucumis melo aqueous extracttreated (CMAE 1, $400 \mathrm{mg} / \mathrm{kg}$ ) group, and group 8 was a Cucumis melo aqueous extract-treated (CMAE 2, 200 $\mathrm{mg} / \mathrm{kg}$ ) group.

\section{Induction of diabetes}

Streptozotocin (STZ) was used for the induction of diabetes in animals; for this, the animals were kept fasting overnight. STZ was given $\mathrm{i} / \mathrm{p}$, in a dose of $55 \mathrm{mg} / \mathrm{kg}$. STZ was prepared in $10 \mathrm{mM}$ citrate buffer $(\mathrm{pH} 4.5)$ and maintained on a high-fat diet [carbohydrate (48\%), fat $(22 \%)$, and protein $(20 \%)$ with the total calorific value of $44.3 \mathrm{~kJ} / \mathrm{kg}$ ] throughout the study. The administration of STZ caused a raised blood glucose level in 1 week. Animals showing increased blood glucose levels of more than $250 \mathrm{mg} / \mathrm{dL}$ were included in the study [22]. It has been reported that low-dose STZ with a high-fat diet produced a natural pattern of diabetes. Single-injection of STZ has shown the highest successful rate (100\%) in rats with increased fasting blood glucose levels and reduced plasma insulin levels [23]. 


\section{Lipid profile}

The lipid profile of animals was determined by collecting the blood from the retro-orbital route of STZ-induced diabetic animals on the 0th, 7th, 14th, 21st, and 28th days. The blood was centrifuged at $4000 \times g$ for $15 \mathrm{~min}$ to collect the serum and analyzed using enzymatic diagnostic kits (Cell Biolabs Inc., USA). The serum was analyzed for lipid profiles such as triglyceride (TG) and highdensity lipoprotein (HDL). However, low-density lipoprotein and very low-density lipoprotein (VLDL) cholesterol were also determined using the Friedewald formula, i.e., LDL cholesterol = total cholesterol $-(\mathrm{HDL}$ + VLDL) [24]. All the analyses were done using an autoanalyzer (Merck, Germany).

\section{Euthanasia}

The animals were given i.v. injection of pentobarbital to depress the central nervous system followed by the stopping of breathing and then by cardiac arrest.

\section{Statistical analysis}

All the values are represented as mean \pm standard error $(n$ = 6), significantly different at ${ }^{*} P<0.05$ in comparison with the positive control group and $\Delta P<0.05$ in comparison with the negative control group analyzed by one-way ANOVA followed by Tukey's multiple comparison test.

\section{Results}

\section{Physicochemical analysis}

The physicochemical parameters of Cucumis melo fruit powder are shown in Table 1 . The results exhibited that foreign matter $0.1 \% \mathrm{w} / \mathrm{w}$, moisture content $9.5 \% \mathrm{w} / \mathrm{w}$, total ash $26.92 \% \mathrm{w} / \mathrm{w}$, water-soluble ash $21.0 \% \mathrm{w} / \mathrm{w}$, acid insoluble ash $10.0 \% \mathrm{w} / \mathrm{w}$, and swelling index 4.04 were present in the fruit powder of C. melo.

\section{Reaction of reagents with powdered drugs}

The powdered drug of $C$. melo was treated with different solvents and reagents such as water, $\mathrm{NaOH}, \mathrm{HNO}_{3}$, $\mathrm{H}_{2} \mathrm{SO}_{4}$, acetone, and $\mathrm{CHCl}_{3}$. Mostly, the dark brown color was obtained. Table 2 shows the different color variations of $C$. melo in daylight and under UV light while treated with different reagents.

Table 1 Physicochemical investigation of Cucumis melo fruit powder

\begin{tabular}{ll}
\hline Parameter & Value $(\%, w / w)$ \\
\hline Foreign matter & 0.1 \\
Moisture content & 9.5 \\
Total ash & 26.92 \\
Water-soluble ash & 21.0 \\
Acid insoluble ash & 10.0 \\
Swelling index & 4.04 \\
\hline
\end{tabular}

Fluorescent analysis of Cucumis melo dried fruit powder Separation of flavonoid

Yellow needle-shaped crystalline powder with sharp melting at $357^{\circ} \mathrm{C}$, soluble in alcohol and chloroform. UV spectrum showed maxima at 256 and $378 \mathrm{~nm}$. The mass spectrum exhibited a molecular ion peak at $318.18 \mathrm{~nm}$ and a prominent base peak at $318.18 \mathrm{~nm}$ (Fig. 1).

\section{Antidiabetic activity of C. melo}

The administration of STZ caused a significant rise in blood glucose levels of more than $250 \mathrm{mg} / \mathrm{dL}$ in all treated groups. Treatment with $C$. melo fruit extract and fraction caused a reduction in blood glucose level from day 7 to the last day of treatment, i.e., the 28th day. $C$. melo toluene fraction (CMTF) of ethanolic extract exhibited significant $\left({ }^{*} P<0.05\right)$ reduction of blood glucose level on the 28th day, i.e., $122 \mathrm{mg} / \mathrm{dL}$ in comparison with the positive control group. The order of glucoselowering capacity of extract-treated groups was CMEE 1 > CMAE 1 > CMEE 2 > CMAE 2 (Table 3).

\section{Antihyperlipidemic activity of C. melo}

STZ caused dyslipidemia in all treated animals, which was restored by the treatment with $C$. melo fraction and extract. Triglyceride, LDL, and VLDL levels were increased chronically due to STZ, and were significantly $(P$ $<0.05$ ) restored to 84.16, 86.97, and 19.73, respectively, by CMTF in comparison with the positive control group (Table 4). However, HDL level was decreased in diabetesinduced animals, which was restored to 38.76 by CMTF. The extract showed dose-dependent restoration property as 92.22, 38.61, 97.01, and 22.83 of TG, HDL, LDL, and VLDL, respectively, by CMEE 1 . Figures $2,3,4$, and 5 show the graphical representation of TG, LDL, VLDL, and HDL profile, respectively, of animals after treated with $C$. melo extract and fraction.

\section{Discussion}

In the present study, C. melo fruit extract was used for the evaluation of antidiabetic and antihyperlipidemic activities. The phytochemical results obtained in our study followed the work of Alagar et al. [25] based on ash values and moisture content. The reaction of crude drug with reagents revealed mostly dark brown color in daylight. Our results are in agreement with Fahamiya et al. [26]. Fluorescent analysis of C. melo shown yellow crystalline powder with UV maxima between 256 and 378 nm. Similar results were reported by Ahmad et al. [21].

In this study, STZ in a dose of $50 \mathrm{mg} / \mathrm{kg}$ body weight was utilized as a diabetogenic operator to prompt diabetes in albino Wistar rats; loss in body weight was observed in STZ-induced diabetic rats. Antidiabetic study of $C$. melo fruit extract revealed that the toluene fraction of ethanolic extract was very potent in lowering 
Table 2 Reaction of different reagents with powdered drugs

\begin{tabular}{|c|c|c|c|c|}
\hline S. no. & Materials/treatment & Daylight (254 nm) & UV light (366 nm) & Color \\
\hline 1 & Dried powder & Light brown & Light brown & Brown \\
\hline 2 & Powder treated with dist. water & Light brown & Light brown & Dark brown \\
\hline 3 & Powder treated with $1 \mathrm{~N} \mathrm{NaOH}$ in water & Dark brown & Light black & Black \\
\hline 4 & Powder treated with $1 \mathrm{~N} \mathrm{NaOH}$ in methanol & Dark brown & Light green & Black \\
\hline 5 & Powder treated with $50 \% \mathrm{HNO}_{3}$ & Brown & Green & Black \\
\hline 6 & Powder treated with $50 \% \mathrm{HCl}$ & Light brown & Light green & Dark brown \\
\hline 7 & Powder treated with conc. $\mathrm{HCl}$ & Dark brown & Light black & Dark black \\
\hline 8 & Powder treated with $\mathrm{H}_{2} \mathrm{SO}_{4}$ & Dark brown & Dark black & Black \\
\hline 9 & Powder treated with acetone & Light green & Green & Light brown \\
\hline 10 & Powder treated with $\mathrm{CHCl}_{3}$ & Light green & Green & Dark brown \\
\hline
\end{tabular}

increased blood glucose levels. This effect of C. melo may be due to the enhanced insulin secretion, more absorption of glucose by skeletal muscle and adipose tissues, inhibition of absorption of glucose from the intestine, and inhibition of glucose production from liver cells [27]. Other reported works on herbal extracts hypothesized that the antidiabetic mechanisms are due to the pancreatic activity of beta cells, inhibition of insulin-degrading enzyme (insulinase), enhanced insulin sensitivity, and insulin-like activity [28]. C. melo leaf extract has reported antidiabetic and antihyperlipidemic activities [29].
The complications of diabetes originating from oxidative stress that may precipitate hypoglycemia postulated that its etiology involves oxidative stress perhaps as a result of hypoglycemia [30]. The elevated levels of blood glucose in diabetes produce oxygen free radicals, which cause membrane damage due to peroxidation of membrane lipids and protein glycation [31]. The action of diabetes-inducing agents produces reactive free radicals, which have been shown to be cytotoxic to the beta cells of the pancreas [32]. The diabetogenic action can be prevented by the superoxide dismutase, catalase, and other hydroxyl radical scavengers such as ethanol and

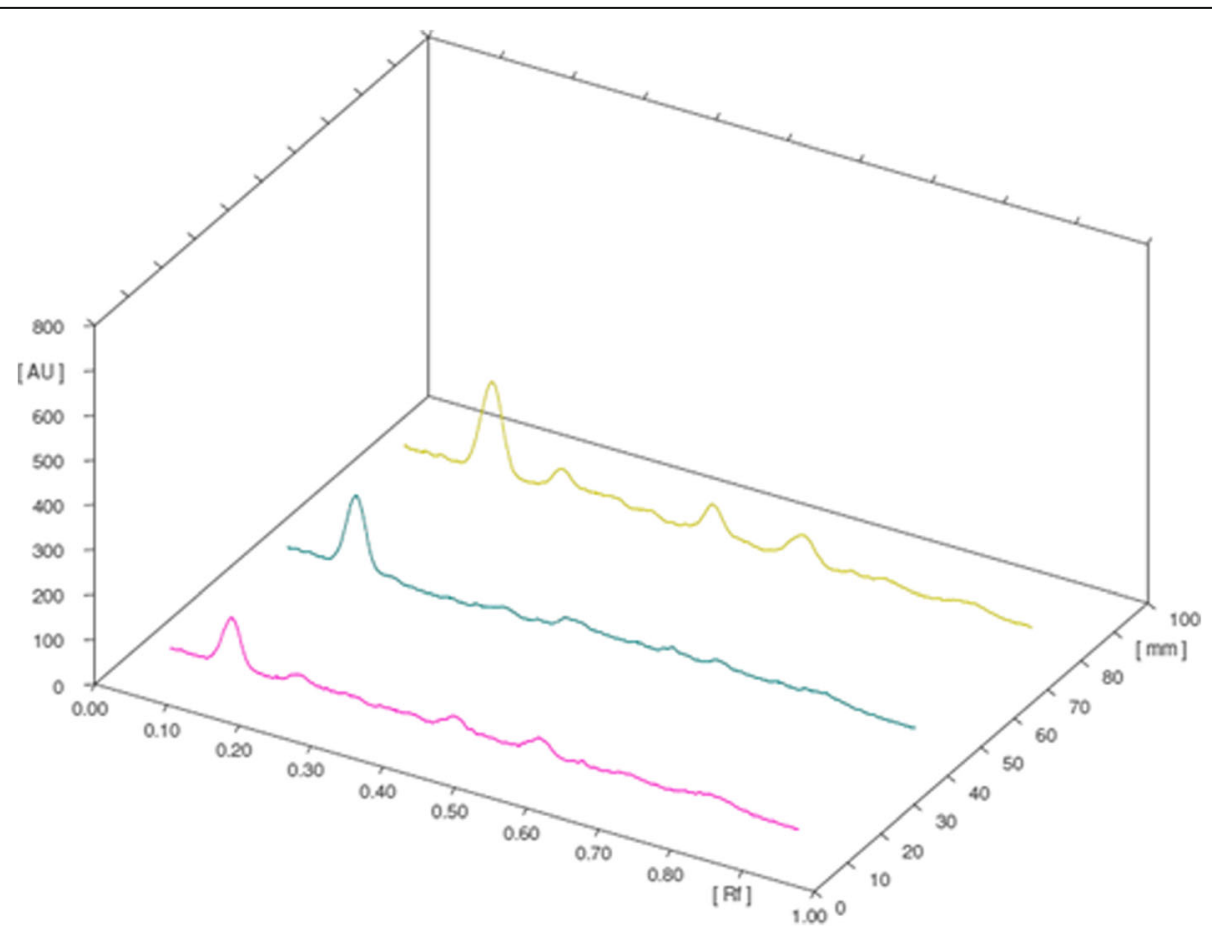

Fig. 1 HPTLC fingerprinting densitogram of C. melo fruit powder. Yellow line, ethanolic extract of C. melo; blue line, standard kaempferol; pink line, toluene fraction of ethanolic extract 
Table 3 Antidiabetic activity of C. melo fraction and extracts

\begin{tabular}{|c|c|c|c|c|c|c|}
\hline \multirow[t]{2}{*}{ Treatment } & \multirow{2}{*}{$\begin{array}{l}\text { Dose } \\
(\mathrm{mg} / \\
\mathrm{kg})\end{array}$} & \multicolumn{5}{|c|}{ Blood glucose level (mg/dl) } \\
\hline & & Day 0 & Day 7 & Day 14 & Day 21 & Day 28 \\
\hline Negative control & - & $88.83 \pm 2.07$ & $102.16 \pm 2.18$ & $109.66 \pm 2.43$ & $107.16 \pm 1.78$ & $76.50 \pm 1.05$ \\
\hline Positive control & - & $299.66 \pm 2.59^{*}$ & $287.66 \pm 2.44^{*}$ & $287.00 \pm 2.11^{*}$ & $288.66 \pm 1.65^{*}$ & $279.50 \pm 1.69^{*}$ \\
\hline References & 10 & $278.50 \pm 1.91$ & $181.33 \pm 2.29 \Delta$ & $144.00 \pm 1.4 \Delta$ & $107.50 \pm 1.4 \Delta$ & $76.16 \pm 1.68 \Delta$ \\
\hline CMTF & 50 & $279.16 \pm 1.40$ & $235.50 \pm 1.34 \triangle$ & $200.16 \pm 1.64$ & $151.83 \pm 1.62 \Delta$ & $122.00 \pm 1.92 \Delta$ \\
\hline CMEE 1 & 400 & $285.83 \pm 1.9$ & $251.83 \pm 2.09$ & $214.66 \pm 0.88 \Delta$ & $178.16 \pm 0.98 \Delta$ & $160.16 \pm 1.62$ \\
\hline CMEE 2 & 200 & $293.13 \pm 0.17$ & $265.16 \pm 0.70$ & $230.12 \pm 0.32$ & $207.19 \pm 0.25$ & $195 \pm 0.39$ \\
\hline CMAE 1 & 400 & $254.35 \pm 0.76$ & $255.29 \pm 0.14$ & $238.94 \pm 0.16$ & $215.89 \pm 0.72 \Delta$ & $190.69 \pm 0.84$ \\
\hline CMAE 2 & 200 & $278.67 \pm 0.13$ & $270.12 \pm 0.32$ & $250.31 \pm 0.89$ & $235.17 \pm 0.54$ & $224.94 \pm 0.23$ \\
\hline
\end{tabular}

Values are expressed as mean \pm standard error of mean $(n=6)$. ${ }^{*} P<0.05$, vs the positive control group; $\Delta P<0.05$, vs the negative control group analyzed by one-way ANOVA followed by Tukey's multiple comparison test

CMTF Cucumis melo toluene fraction (ethanolic extract), CMEE 1 Cucumis melo ethanolic extract (400 mg/kg), CMEE 2 CUCumis melo ethanolic extract (200 mg/kg), CMAE 1 CUcumis melo aqueous extract $(400 \mathrm{mg} / \mathrm{kg})$, CMAE 2 Cucumis melo aqueous extract $(200 \mathrm{mg} / \mathrm{kg})$

dimethyl urea; hence, there is evidence to suggest that the incidence of diabetes involves superoxide anion and hydroxyl radicals. There is clear cut evidence to show the role of free radicals in diabetes, and studies indicate that tissue injury in diabetes may be due to the free radicals.

Thus, the fruit extract of C. melo was evaluated for these biological activities. The active constituents found in $C$. melo seeds are phenolic acid (caffeic acid, gallic acid, rosmarinic acid, and protocatechuic acid), flavonoids (naringenin, apigenin, secoiridoids, luteolin-7-O-glycosides, pinoresinol, and amentoflavone), fatty acid (myristic acid, palmitic acid, stearic acid, arachidic acid, plamitoleic acid, oleic acid, linoleic acid, and linolenic acid), sterols (campesterol, stigmasterol, $\beta$-sitosterol, cholesterol, and brassicasterol), and tocopherol contents [33].

Especially, insulin deficiency provokes diabetic patients more prone to hypercholesterolemia and hypertriglyceridemia [34]. One of the major pathogenesis of lipid metabolism disturbances in diabetes is the increased mobilization of fatty acids from adipose tissue and secondary elevation of the free fatty acid levels in the blood. One of the consequences of excessive mobilization of fatty acid is the production of ketone bodies in the liver. Excessive lipolysis remnants, i.e., free fatty acids, enter the liver and are esterified to form triglycerides [35]. Fatty acids are required for both the structure and function of every cell in the body, and they form an important component of cell membranes. Several authors have reported that the fatty acid compositions of various tissues are altered in both experimental and human diabetes [36, 37].

It has been reported that there is a direct correlation between diabetes and dyslipidemia. Diabetic patients have two- to fourfold higher risk of coronary artery disease; this condition is also termed as diabetic dyslipidemia [38]. Diabetic dyslipidemia is associated with raised triglycerides level and reduced HDL level. It is due to insulin resistance or deficient lipid metabolism in diabetes [39]. In our study, C. melo fruit extract significantly reduced blood glucose levels due to its antidiabetic potential and thus restored the

Table 4 Antihyperlipidemic activity of C. melo fraction and extracts

\begin{tabular}{llllll}
\hline Groups & Dose $(\mathbf{m g} / \mathbf{k g})$ & TG $(\mathbf{m g} / \mathbf{d l})$ & LDL $(\mathbf{m g} / \mathbf{d l})$ & VLDL $(\mathbf{m g} / \mathbf{d l})$ & HDL $(\mathbf{m g} / \mathbf{d l})$ \\
\hline Negative control & - & $71.83 \pm 0.7$ & $72.83 \pm 0.72$ & $10.65 \pm 0.49$ & $48.32 \pm 1.9$ \\
Positive control & - & $117.66 \pm 1.47^{*}$ & $159.55 \pm 1.03^{*}$ & $47.12 \pm 0.93^{*}$ & $18.08 \pm 1.28^{*}$ \\
Reference & 10 & $78.16 \pm 1.56 \Delta$ & $76.26 \pm 0.32 \Delta$ & $14.09 \pm 0.69 \Delta$ & $45.86 \pm 1.47 \Delta$ \\
CMTF & 50 & $84.16 \pm 0.7 \Delta$ & $86.97 \pm 0.34 \Delta$ & $19.73 \pm 1.2 \Delta$ & $38.76 \pm 2.68 \Delta$ \\
CMEE 1 & 400 & $92.22 \pm 0.84 \Delta$ & $97.01 \pm 1.05 \Delta$ & $22.83 \pm 0.33 \Delta$ & $38.61 \pm 63 \Delta$ \\
CMEE 2 & 200 & $102.33 \pm 0.29$ & $113.16 \pm 0.89$ & $38.87 \pm 1.13$ & $44.33 \pm 0.32$ \\
CMAE 1 & 400 & $100.13 \pm 0.23$ & $105.16 \pm 0.56$ & $29.45 \pm 0.05$ & $42.05 \pm 0.14$ \\
CMAE 2 & 200 & $105.12 \pm 0.46$ & $116.49 \pm 1.10$ & $41.54 \pm 0.45$ & $44.1 \pm 0.43$ \\
\hline
\end{tabular}

Values are expressed as mean \pm standard error of mean $(n=6)$, significantly different at $* P<0.05$, vs the normal control group; $\Delta P<0.05$, vs the diabetic control group analyzed by one-way ANOVA followed by Tukey's multiple comparison test

CMTF Cucumis melo toluene fraction (ethanolic extract), CMEE 1 Cucumis melo ethanolic extract (400 mg/kg), CMEE 2 Cucumis melo ethanolic extract (200 mg/kg), CMAE 1 CUcumis melo aqueous extract ( $400 \mathrm{mg} / \mathrm{kg})$, CMAE 2 Cucumis melo aqueous extract $(200 \mathrm{mg} / \mathrm{kg})$ 


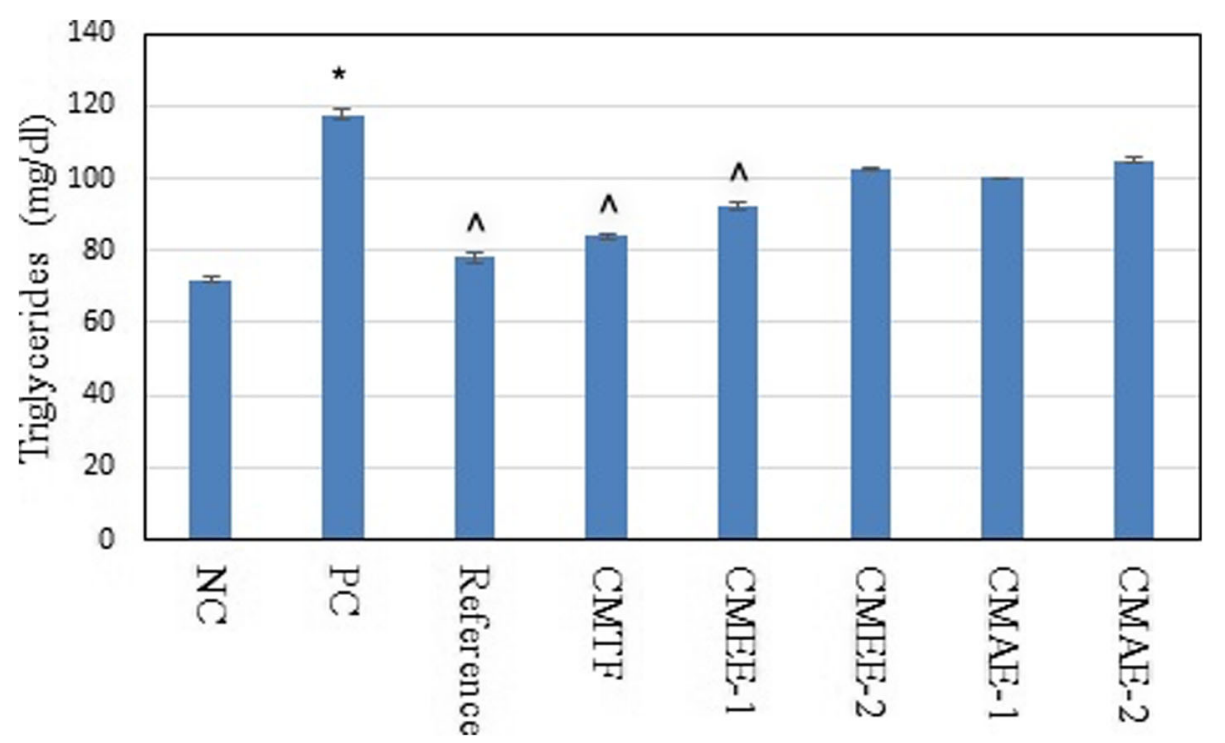

Fig. 2 Effect of $C$. melo fraction and extracts on the TG level of animals. Values are expressed as mean \pm standard error of mean $(n=6)$, significantly different at ${ }^{*} P<0.05$, vs the normal control group; $\Delta P<0.05$, vs the diabetic control group analyzed by one-way ANOVA followed by Tukey's multiple comparison test. CMTF, Cucumis melo toluene fraction (ethanolic extract); CMEE 1, Cucumis melo ethanolic extract (400 mg/kg); CMEE 2, Cucumis melo ethanolic extract (200 mg/kg); CMAE, Cucumis melo aqueous extract ( $400 \mathrm{mg} / \mathrm{kg}) ;$ CMAE, Cucumis melo aqueous extract $(200 \mathrm{mg} / \mathrm{kg})$

lipid profile of diabetic rats. Our results were in agreement with Ahmed et al. [40], who reported that fruit extract possesses the ability to normalize blood glucose levels with a hypotriglyceridemic effect in STZ-induced diabetic rats.
Diabetes is also known to be associated with an increase in the synthesis of cholesterol, which may be due to the increased activity of HMG CoA reductase. A number of observations indicate that plasma HDL cholesterol is low in untreated insulin-deficient diabetics [41, 42], which was

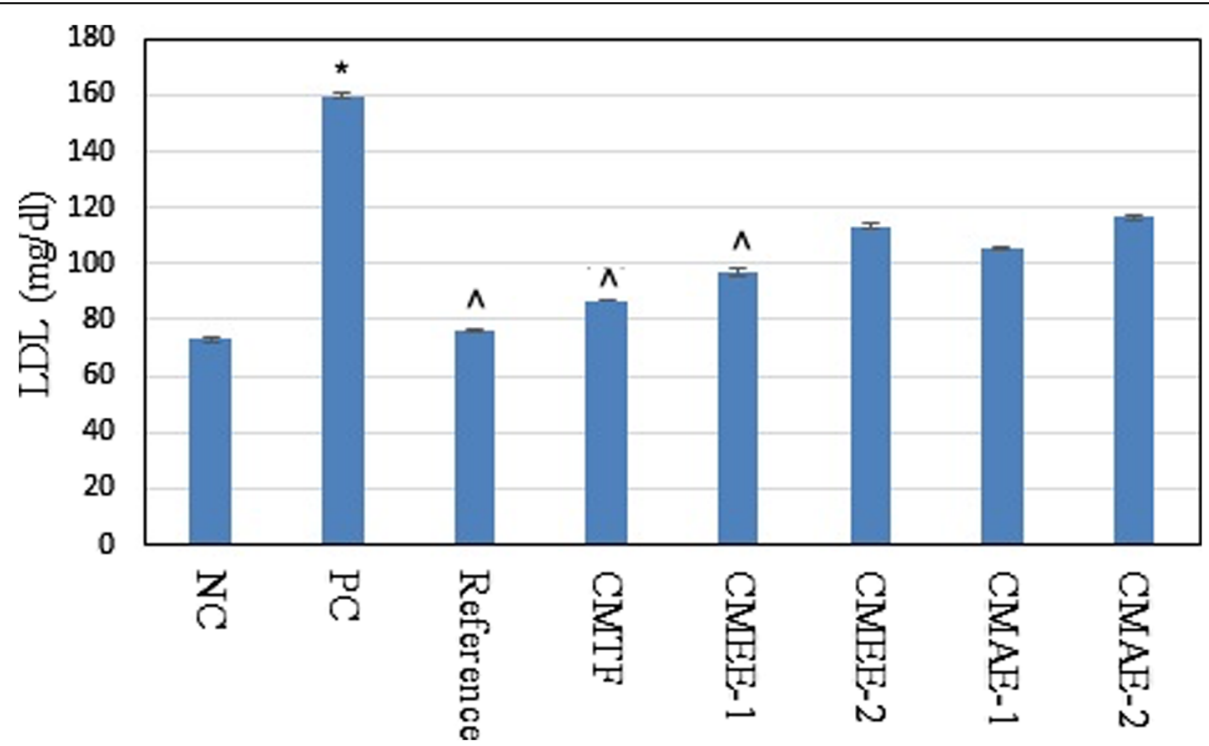

Fig. 3 Effect of $C$. melo fraction and extracts on the LDL level of animals. Values are expressed as mean \pm standard error of mean $(n=6)$, significantly different at ${ }^{*} P<0.05$, vs the normal control group; $\Delta P<0.05$, vs the diabetic control group analyzed by one-way ANOVA followed by Tukey's multiple comparison test. CMTF, Cucumis melo toluene fraction (ethanolic extract); CMEE 1, Cucumis melo ethanolic extract (400 mg/kg); CMEE 2, Cucumis melo ethanolic extract (200 mg/kg); CMAE, Cucumis melo aqueous extract (400 mg/kg); CMAE, Cucumis melo aqueous extract $(200 \mathrm{mg} / \mathrm{kg}$ ) 


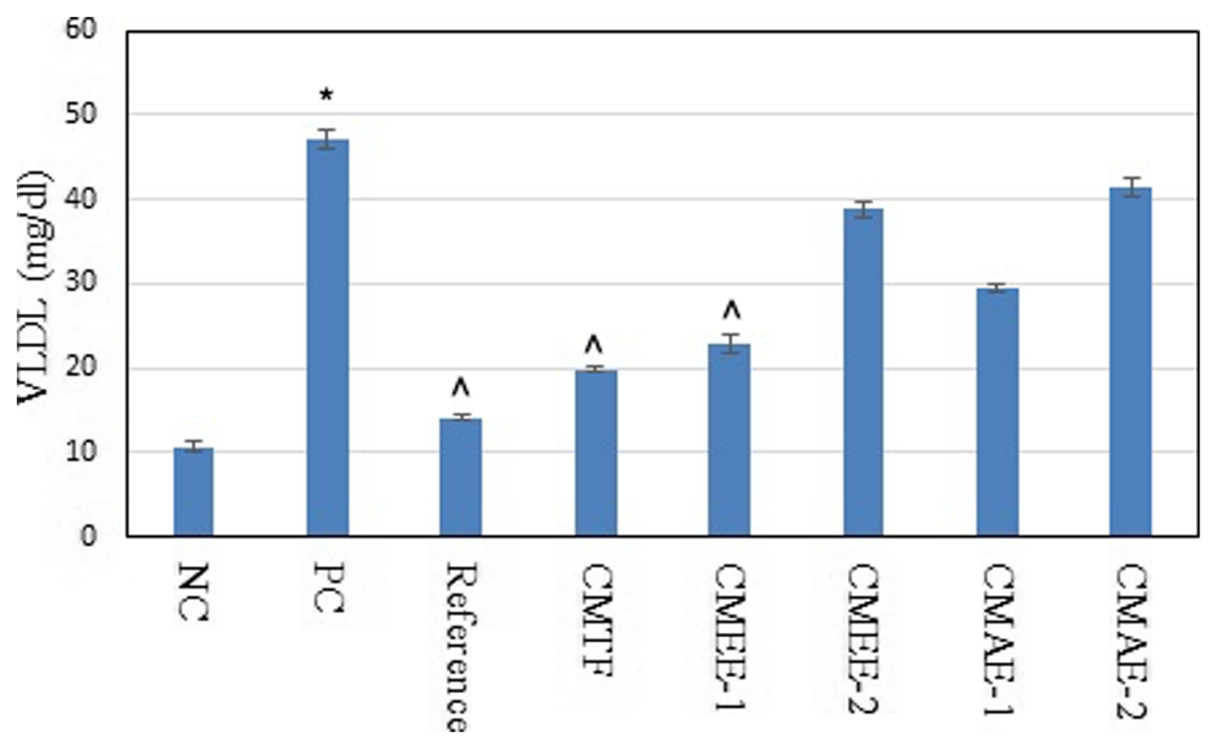

Fig. 4 Effect of C. melo fraction and extracts on the VLDL level of animals. Values are expressed as mean \pm standard error of mean $(n=6)$, significantly different at ${ }^{*} P<0.05$, vs the normal control group; $\Delta P<0.05$, vs the diabetic control group analyzed by one-way ANOVA followed by Tukey's multiple comparison test. CMTF, Cucumis melo toluene fraction (ethanolic extract); CMEE 1, Cucumis melo ethanolic extract (400 mg/kg); CMEE 2, Cucumis melo ethanolic extract (200 mg/kg); CMAE, Cucumis melo aqueous extract ( $400 \mathrm{mg} / \mathrm{kg}) ;$ CMAE, Cucumis melo aqueous extract $(200 \mathrm{mg} / \mathrm{kg})$

associated with a decline in HDL turnover rate. Further, the HDL cholesterol levels correlate with lipoprotein lipase (LPL) levels in IDDM patients. It is shown that VLDL and chylomicrons contribute surface apoproteins and lipids to HDL during hydrolysis by LPL. Increased LDL cholesterol from glycosylation has the ability to form lipid peroxides which was found specifically responsible for the atherogenesis in diabetic patients [43]. There are reports that hypercholesterolemia in streptozotocin-induced diabetes in rats results from increased intestinal absorption and synthesis of cholesterol. Lipoproteins from diabetic rats are oxidized and demonstrate cytotoxicity, a feature

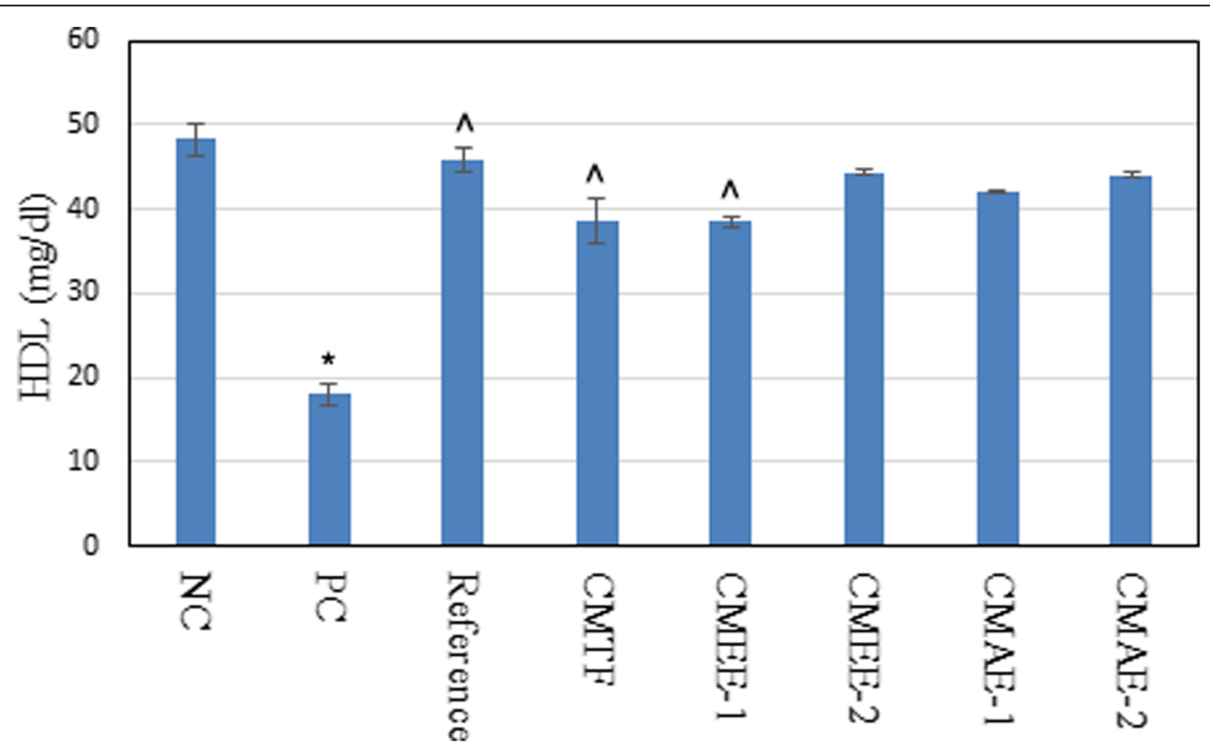

Fig. 5 Effect of $C$. melo fraction and extracts on the HDL level of animals. Values are expressed as mean \pm standard error of mean $(n=6)$, significantly different at ${ }^{*} P<0.05$, vs the normal control group; $\Delta P<0.05$, vs the diabetic control group analyzed by one-way ANOVA followed by Tukey's multiple comparison test. CMTF, Cucumis melo toluene fraction (ethanolic extract); CMEE 1, Cucumis melo ethanolic extract (400 mg/kg); CMEE 2, Cucumis melo ethanolic extract (200 mg/kg); CMAE, Cucumis melo aqueous extract $(400 \mathrm{mg} / \mathrm{kg})$; CMAE, Cucumis melo aqueous extract $(200 \mathrm{mg} / \mathrm{kg})$ 
which can be prevented by insulin or antioxidant treatment [44]. Oral administration of plant extracts normalized these effects, possibly by controlling the hydrolysis of certain lipoproteins and their selective uptake and metabolism by different tissues. The breakdown product of fat causes hypertriglyceridemia in diabetes mellitus and is responsible for vascular complications [45]. Bruan and Severson [46] have reported that deficiency of lipoprotein lipase (LPL) activity may contribute significantly to the elevation of triglycerides in diabetes. Lopes-Virella et al. [47] reported that treatment of diabetes with insulin served to lower plasma triglyceride levels by the restoration of triglycerides levels following extract treatment which is supported by the above reports. Thus, it may be concluded plant extracts may have a stimulatory effect on insulin. The elevated serum phospholipid levels are a consequence of elevated lipoproteins. The serum cholesterol/ phospholipid ratio is one of the important markers of the development of atherosclerosis. The restoration of phospholipids by plant extract may be controlled mobilization of serum triglycerides; controlling the tissue metabolism and improving the level of insulin secretion and action presumably mediate cholesterol and phospholipids.

\section{Conclusion}

It was found that toluene fraction of $C$. melo fruit extract and ethanolic extract in $400 \mathrm{mg} / \mathrm{kg}$ was most effective against diabetes and dyslipidemia. A high level of TG with low levels of HDL exhibited a strong association with diabetes. It is can be concluded that $C$. melo fruits can be used as an effective antidiabetic and antihyperlipidemic drug.

\begin{abstract}
Abbreviations
T1DM: Type 1 diabetes mellitus; T2DM: Type 2 diabetes mellitus; LDL: Lowdensity lipoprotein; HDL: High-density lipoprotein; VLDL: Very low-density lipoprotein; TG: Triglycerides; CMTF: Cucumis melo toluene fraction; CMEE: Cucumis melo ethanolic extract; CMAE: Cucumis melo aqueous extract: STZ: Streptozotocin; HMG-CoA: 3-Hydroxy-3-methylglutaryl-coenzyme A; PPAR: Peroxisome proliferator-activated receptor-gamma
\end{abstract}

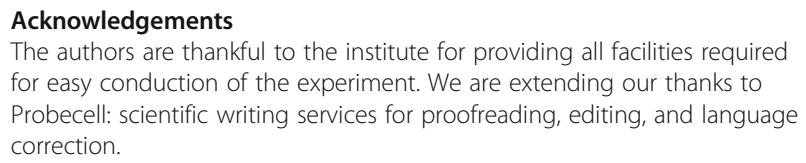
for easy conduction of the experiment. We are extending our thanks to Probecell: scientific writing services for proofreading, editing, and language correction.

\section{Statement}

The ripe fruits of Cucumis melo var. momordica were collected from the gangatic areas of district Allahabad during the spring season. The fruits were identified and authenticated by the Botanical Survey of India with voucher specimen number GC 950221.

\section{Authors' contributions}

All authors have read and approved the final manuscript. AKS designed the work. AM drafted the work or substantively revised it. AT contributed to the acquisition, analysis, and interpretation of the data.

\section{Funding}

No funding was received.

\section{Availability of data and materials}

All data and materials are available upon request.

Ethics approval and consent to participate

The animal study was approved by the Institutional Animal Ethical Committee (Approval No. UIP/IAEC/2014/April/23).

\section{Consent for publication}

Not applicable.

\section{Competing interests}

There is no competing interest.

Received: 30 December 2019 Accepted: 21 September 2020

Published online: 20 November 2020

\section{References}

1. Bommer C, Heesemann E, Sagalova V, Manne-Goehler J, Atun R, Barnighausen $T$ (2017) The global economic burden of diabetes in adults aged 20-79 years: a cost-of-illness study. Lancet Diabetes Endocrinol 5:423430

2. Meldgaard T, Brock C (2019) Diabetes and the gastrointestinal tract. Med (United Kingdom) 47(7):454-459

3. Bacanli M, Dilsiz SA, Başaran N, Başaran AA (2019) Effects of phytochemicals against diabetes. Adv Food Nutr Res:1-30

4. Kavvoura FK, Owen KR (2019) Monogenic diabetes. Med (United Kingdom) 47(1):16-21

5. Atkinson MA, Eisenbarth GS, Michels AW (2014) Type 1 diabetes. Lancet 383: 69-82

6. Kumar V, Robinson AHN (2019) Diabetes and orthopaedic surgery: a review. Orthop Traumatol:1-5

7. Mollazadeh H, Mahdian D, Hosseinzadeh H (2019) Phytomedicine medicinal plants in treatment of hypertriglyceridemia: a review based on their mechanisms and effectiveness. Phytomedicine. 53:43-52

8. Hernández RJ, Mahmoud AM, Königsberg M, López NE, Guerrero D (2019) Obesity: pathophysiology, monosodium glutamate-induced model and antiobesity medicinal plants. Biomed Pharmacother 111:503-516

9. Krauss RM (2004) Lipids and lipoproteins in patients with type 2 diabetes. Diabetes Care 27:1496-1504

10. Rahmani AH, Al Zohairy MA, Aly SM, Khan MA. (2014) Curcumin: a potential candidate in prevention of cancer via modulation of molecular pathways. BioMed Research International, 1-15.

11. Alexandra M, Gonçalves T, Alves RC, Oliveira MBPP, Costa HS. (2018) Melon (Cucumis melo L.) by-products: potential food ingredients for novel functional foods? Trends Food Sci Technol. 1-9.

12. Singh AK, Kumar S, Singh H, Rai VP, Singh BD, Pandey S (2015) Genetic diversity in Indian snapmelon (Cucumis melo var. momordica) accessions revealed by ISSR markers. POJ. 8(1):9-16

13. Szamosi C, Solmaz I, Sari N, Bã C (2010) Morphological evaluation and comparison of Hungarian and Turkish melon (Cucumis melo L.) germplasm. Sci Hortic 124(2):170-182

14. Sabanadzovic S, Wintermantel WM, Valverde RA, Mccreight JD (2016) Aboughanem-sabanadzovic N. Cucumis melo endornavirus: genome organization, host range and co-divergence with the host. Virus Res 214:49-58

15. Srivastava AK, Mukerjee A, Ramteke PW, Pandey H, Mishra SB (2017) Antiulcer potential of Cucumis melo var. momordica (Roxb), Duthie \& Fuller fruits in experimental animal. J Pharm Res 16(3):218-223

16. Vishwakarma VK, Gupta JK, Upadhyay PK (2017) Pharmacological importance of Cucumis melo L:: an overview. Asian J Pharm Clin Res 10(3):8-12

17. Waseem M, Rauf A, Rehman S, Ahmed R. (2018) Pharmacognostical and pharmacological review of Cucumis melo L. including Unani medicine perspective. Int J Pharmacogn Chinese Med. 1-8.

18. Bidkar J (2012) Anti-hyperlipidemic activity of Cucumis melo fruit peel extracts in high cholesterol diet induced hyperlipidemia in rats. Journal of Complementary and Integrative Medicine 9(1):1-18

19. Zhang X, Bai Y, Wang Y, Wang C, Fu J, Gao L, et al. Anticancer properties of different solvent extracts of Cucumis melo L. seeds and whole fruit and their metabolite profiling using HPLC and GC-MS. Kabir Y, editor. Biomed Res Int. 2020.

20. Mushtaq A, Akbar S, Zargar MA, Wali AF, Malik AH, Dar MY, Hamid R, Ganai BA. (2014) Phytochemical screening, physicochemical properties, acute 
toxicity testing and screening of hypoglycaemic activity of extracts of Eremurus himalaicus baker in normoglycaemic Wistar strain albino rats. BioMed Research International. 1-6.

21. Ahmad Ml, Ansari SH, Naquvi KJ, Shuaib M (2012) Pharmacognostical studies and establishment of quality parameters of Cucumis melo L. CV. namdhari. Int J Pharm Pharm Sci 4:324-329

22. Gandhi GR, Sasikumar P (2012) Antidiabetic effect of Merremia emarginata Burm. F. in streptozotocin induced diabetic rats. Asian Pac J Trop Biomed 2(4):281-286

23. Zhang $M, L v X-Y, L i J, X u Z G$, Chen $L$ (2008). The characterization of high-fat diet and multiple low-dose streptozotocin induced type 2 diabetes rat model. Kern T, editor. Exp Diabetes Res.

24. Choudhari VP, Gore KP, Pawar AT (2017) Antidiabetic, antihyperlipidemic activities and herb-drug interaction of a polyherbal formulation in streptozotocin induced diabetic rats. J Ayurveda Integr Med 8(4):218-225

25. Alagar RM, Sahithi G, Vasanthi R, David B, Rao KNV, Selvakumar D (2015) Study of phytochemical and antioxidant activity of Cucumis melo var. agrestis fruit study of phytochemical and antioxidant activity of Cucumis melo var. agrestis fruit. Journal of Pharmacognosy and Phytochemistry 4(2):303-306

26. Fahamiya N, Aslam M, Siddiqui A, Shiffa M, Ahmed A, Khan MS (2012) Pharmacognostical study and development of quality control parameters for Cucumis melo Linn. Am J PharmTech Res 2(4):1-14

27. Kooti W, Farokhipour M, Asadzadeh Z, Ashtary-Larky D, Asadi-Samani M (2016) The role of medicinal plants in the treatment of diabetes: a systematic review. Electron Physician 8(1):1832-1842

28. Mahdizadeh R, Moein S, Soltani N, Malekzadeh K, Moein M (2018) Study the molecular mechanism of Salvia species in prevention of diabetes. Int J Pharm Sci Res 9(11):4512-4521

29. Ibrahim DS, Abd El-Maksoud MA (2018) Antioxidant and antidiabetic activities of Cucumis melo var. Flexuosus leaf extract. Indian J Physiol Pharmacol 62(4):445-452

30. Hunt JV, Smith CC, Wolff SP (1990) Auto-oxidative glycosylation and possible involvement of peroxides and free radicals in LDL modification by glucose. Diabetes. 39:1420-1424

31. Sato Y, Hotto N, Sakamoto N, Matsuoka S, Ohishi N, Yafi K (1979) Lipid peroxide level in plasma of diabetic patients. Biochemical Medicine 2:104-107

32. Heikkila RG, Winston B, Cohen G, Barden H (1976) Alloxan induced diabetes: evidence of hydroxyl radical as a cytotoxic intermediate. Biochem Pharmacol 25:1085-1092

33. Mallek-Ayadi S, Bahloul N, Kechaou N (2018) Chemical composition and bioactive compounds of Cucumis melo L. seeds: potential source for new trends of plant oils. Process Saf Environ Prot 113:68-77

34. Jaiprakash R, Naga Rani MA, Venkataraman BV (1993) Effect of felodipine on serum lipid profile in short term streptozotocin diabetes in rats. Indian J Exp Biol 1:283-284

35. Hem DA (1977) Exploration and exploitation. In: Hem DA (ed) Biologically active substances. John Wiley \& Sons, Chichester, New York, p 209

36. Faas FH, Dang AQ, Norman J, Carter WJ (1988) Red blood cell and plasma fatty acid composition in diabetes mellitus. Metabolism. 37:711-713

37. Tilvis RS, Miettinen TA (1985) Fatty acid composition of serum lipids, erythrocytes and platelets in insulin-dependent diabetic women. J Clin Endocrinol Metab 61:741-745

38. Bhowmik B, Siddiquee T, Mujumder A, Afsana F, Hussain A, Holmboeottesen $G$ (2018) Serum lipid profile and its association with diabetes and prediabetes in a rural. Bangladeshi population 15(9):1-12

39. Ozder A (2014) Lipid profile abnormalities seen in T2DM patients in primary healthcare in Turkey: a cross-sectional study. Lipids Health Dis 13:183

40. Ahmed I, Lakhani MS, Gillett M, John A, Raza H (2001) Hypotriglyceridemic and hypocholesterolemic effects of anti-diabetic Momordica charantia (karela) fruit extract in streptozotocin-induced diabetic rats. Diabetes Res Clin Pract 51(3):155-161

41. Goodman MW, Michels LD, Keane WF (1982) Intestinal and hepatic cholesterol synthesis in the alloxan diabetic rats. Proc Soc Exp Biol Med 170:286-290

42. Glasgow AM, August GP, Hung W (1981) Relationship between control and serum lipids in juvenile onset diabetes. Diabetes Care 4:76-80

43. Kondo A, Muranaka Y, Ohta I, Notsu K, Manabe M, Kotani K, Saito K, Mackawa M, Kanno T (2001) Relationship between tgandariglyceride concentrations and LDL size evaluated by malondialdehyde-modified LDL. Clin Chem 47:893-900

44. Mathe D (1995) Dyslipidemia and diabetes: animal models. Diabete Metab 21:106-111
45. Kudchodkar BJ, Lee JC, Lee SM, DiMarco NM, Lacko A (1988) Effect on cholesterol homeostasis in diabetic rats. J Lipid Res 29:1272-1287

46. Bruan JE, Severson DL (1992) Lipoprotein lipase release from cardiac myocytes is increased by decavandate but not insulin. Am J Phys 262:663-670

47. Lopes-Virella MF, Whitmann HJ, Mayfield PK, Loadhott CB, Colwell JA (1983) Effect of metabolic control on lipid, lipoprotein and apolipoprotein levels in 55 insulin-dependent diabetic patients: a longitudinal study. Diabetes. 32:20-25

\section{Publisher's Note}

Springer Nature remains neutral with regard to jurisdictional claims in published maps and institutional affiliations.

\section{Submit your manuscript to a SpringerOpen ${ }^{\circ}$ journal and benefit from:}

- Convenient online submission

- Rigorous peer review

- Open access: articles freely available online

- High visibility within the field

- Retaining the copyright to your article

Submit your next manuscript at $\boldsymbol{\nabla}$ springeropen.com 